\title{
Articles
}

\section{Factors Influencing Survival of Female Elk in a Harvested Population}

\author{
Jonathan M. Conard,* Brett K. Sandercock, Philip S. Gipson, Warren B. Ballard \\ J.M. Conard, B.K. Sandercock \\ Division of Biology, Kansas State University, Manhattan, Kansas 66506 \\ Present address of J.M. Conard: Natural Science Department, Sterling College, Sterling, Kansas 67579
}

P.S. Gipson, W.B. Ballard'

Department of Natural Resource Management, Texas Tech University, Lubbock, Texas 79409

${ }^{1}$ Deceased, January 2012

\begin{abstract}
Understanding the influence of management actions and environmental conditions on demographic vital rates is important for effective conservation and management of wildlife populations. We used radio-telemetry to monitor annual and seasonal survival of 34 female elk Cervus elaphus at Fort Riley, Kansas in a 3.5-y field study (November 2003 to February 2007). We modeled the relationship between individual and environmental covariates and survival rates of female elk. We observed eight mortalities, and harvest was the primary cause of mortality in our study population. Annual survival rates of female elk in Kansas (0.76) were similar to other harvested populations of elk. Among the candidate model set, models that included age as a covariate were most supported. Parameter estimates from top models provided support for a slight negative relationship between age and survival. Monthly survival estimates during hunting season declined with age from 0.98 for 1.5 -y-old females to 0.80 for 16.5 -y-old females.
\end{abstract}

Keywords: Cervus elaphus; demography; elk; mortality; survival

Received: August 24, 2011; Accepted: July 3, 2012; Published Online Early: August 2012; Published: December 2012 Citation: Conard JM, Sandercock BK, Gipson PS, Ballard WB. 2012. Factors influencing survival of female elk in a harvested population. Journal of Fish and Wildlife Management 3(2):199-208; e1944-687X. doi:10.3996/082011-JFWM-050

Copyright: All material appearing in the Journal of Fish and Wildlife Management is in the public domain and may be reproduced or copied without permission unless specifically noted with the copyright symbol $\odot$. Citation of the source, as given above, is requested.

The findings and conclusions in this article are those of the author(s) and do not necessarily represent the views of the U.S. Fish and Wildlife Service.

* Corresponding author: jconard@sterling.edu

\section{Introduction}

Knowledge of demographic rates of wildlife populations can be used to assess habitat quality, estimate population viability, and determine management strategies (Beissinger and Westphal 1998; Eberhardt 2002; Morris and Doak 2002). In long-lived vertebrates, survival of adult females is the vital rate that generally has the greatest relative influence on overall rates of population change (Nelson and Peek 1982; Gaillard et al. 2000). Sources of mortality for ungulate populations include predation, winter weather, starvation, disease, and harvest (DelGiudice et al. 2002; Raedeke et al. 2002). However, in areas without wolves Canis lupus, predation may not play a large role in regulating elk Cervus elaphus populations (Ballard et al. 2000). Similarly, winter conditions may not have a large influence on survival rates for elk in the southern extent of their range in areas with relatively mild climates (Ballard et al. 2000; Larkin et al. 2003). In addition, density-dependent effects of disease or competition may have little impact on recovering or newly established populations (Bender et al. 2007). Harvest, poaching, or other human-caused mortality sources may be the primary determinant of adult survival rates in areas where other factors, including predation, population density and winter conditions, have relatively little impact. Given that realized rates of population change $(\lambda)$ are influenced by both the elasticity and variability of population vital rates (De Kroon et al. 2000; Gaillard et al. 2000), it is 
critical to identify factors that influence adult female survival in managed populations.

We report on the environmental factors affecting adult survival rates in a managed population of elk in a tallgrass prairie region of Kansas. In many populations of elk, the primary causes of adult mortality are humanrelated (Unsworth et al. 1993; Cole et al. 1997; Ballard et al. 2000; Raedeke et al. 2002). Management practices can mediate the influence of human-related mortality factors on survival of elk. For example, harvest rates may depend on road density, hunter access, or the total number of permits issued (Gratson and Whitman 2000; Hayes et al. 2002). Limiting vehicle access can also reduce elk mortality from poaching and vehicle collisions (Cole et al. 1997). Patterns of habitat selection and use of refuge areas by elk may also influence the vulnerability of elk to harvest (Unsworth et al. 1993; Beringer et al. 1998). In tallgrass prairie systems with little available concealment cover, selective use of habitat and refuge areas by elk may be a critical factor influencing survival, although to our knowledge survival of elk in this context has not been extensively studied.

Nutritional condition also influences the relative vulnerability of elk to harvest or natural mortality (Bender et al. 2006, 2008). Elk that are in poor nutritional condition may be less alert, choose riskier habitats for foraging activity, and be less likely to flee from perceived threats. Similarly, gestation, parturition, and lactation impose high energetic demands on adult females and influence survival rates (Moyes et al. 2006). Individual characteristics, including age and body condition, may influence survival of ungulates, with a potentially increased mortality risk for old or young age classes (Solberg et al. 2000; DelGiudice et al. 2002).

We report on factors affecting adult survival rates in a small harvested population of elk in northeast Kansas. The goals of this study were to 1) estimate monthly and annual survival rates for female elk at Fort Riley Military Reservation, Kansas; 2) determine the influence of habitat use, nutritional condition, and harvest-related variables on female elk survival rates; and 3) compare survival rates and mortality causes with published rates reported for elk populations under different ecological conditions in other parts of their range. Understanding factors that impact survival of elk in this setting may be useful in guiding conservation and management strategies for small harvested populations.

\section{Study Site}

The study was conducted at Fort Riley Military Installation, Kansas (Figure 1). Fort Riley is a $403-\mathrm{km}^{2}$ military reservation located in portions of Geary, Riley, and Clay counties in the Flint Hills ecoregion of northeastern Kansas. The topography of Fort Riley is representative of the Flint Hills region, with rolling hills of tallgrass prairie interspersed with gallery forest along ravines and lowland areas. Small food plots of winter wheat, corn, alfalfa, grain sorghum, and soybeans were planted on some areas of Fort Riley to benefit wildlife populations.
Undeveloped training areas comprised $\sim 264 \mathrm{~km}^{2}$ of the installation, and training activities included artillery firing, small arms firing, combat vehicle operations, and field encampments. The training areas of the installation included a $56-\mathrm{km}^{2}$ artillery and range firing impact area (Impact Zone), which was off limits at all times to civilians and military personnel due to live-fire training exercises and unexploded ordnance.

Elk were historically present in Kansas, but were extirpated by the early 1900s. A reintroduced population of elk at Fort Riley was established with the release of 12 animals from Maxwell Wildlife Refuge, Kansas, in 1986 (Pitts et al. 1987). Additional elk were translocated to Fort Riley from Maxwell Wildlife Refuge in 1987 ( $N=7), 1990$ $(N=2)$, and $1992(N=2)$. Further translocations were made from source herds in Trinidad, Colorado (1988, $N=$ 5), Moise, Montana (1990, $N=8$ ), and Wind Cave National Park, South Dakota (1994, $N=18$ ) for a total of 54 elk released. The total size of the elk population was estimated to be between 75 and 100 individuals based on aerial surveys conducted annually during the study period (Conard 2009). Following successful establishment, a limited annual harvest was initiated in 1990. From 2003 to 2006, the population was managed with issuance of 6-9 either-sex permits and 15-33 antlerlessonly elk permits for a 3-mo season from 1 October to 31 December. Permits were valid for a designated 1-mo period within each 3-mo season (1-31 October, 1-30 November, or 1-31 December). Following regular season on Fort Riley, harvest of elk on private lands adjacent to Fort Riley was open from 1 January to 15 March.

\section{Methods}

\section{Capture procedures}

We captured 30 female elk during the following capture periods: 26-27 October 2003, 4-5 February 2005, 11-13 November 2005, and 14 April 2006 at Fort Riley, Kansas. We captured elk by aerial darting from a helicopter using carfentanil citrate and xylazine hydrochloride for immobilization. We removed a vestigial upper canine from immobilized elk $(N=24)$ to determine age by counting cementum annuli (Dimmick and Pelton 1996). We scored rump body condition, and measured subcutaneous rump-fat thickness levels for all of the elk that we captured using aerial darting (Stephenson et al. 1998). We outfitted each elk with a global positioning system (GPS) collar equipped with a very high frequency (VHF) radio-transmitter $(164-\mathrm{mHz}$ range), remote-release mechanism and mortality sensor (G2000; Advanced Telemetry Systems, Inc., Isanti, MN) or a VHF radio-collar equipped with a mortality sensor (Telemetry Solutions, Concord, CA; Figure 2). Following processing of immobilized elk, we administered naltrexone and tolazoline as an antagonist. We captured an additional four female elk (one yearling, three adults) using corral trapping during the study period and outfitted these elk with GPS radio-collars (G2000; Advanced Telemetry Systems, Inc.).

We attempted to recapture and place new radiocollars on previously captured female elk $(N=12)$ during 


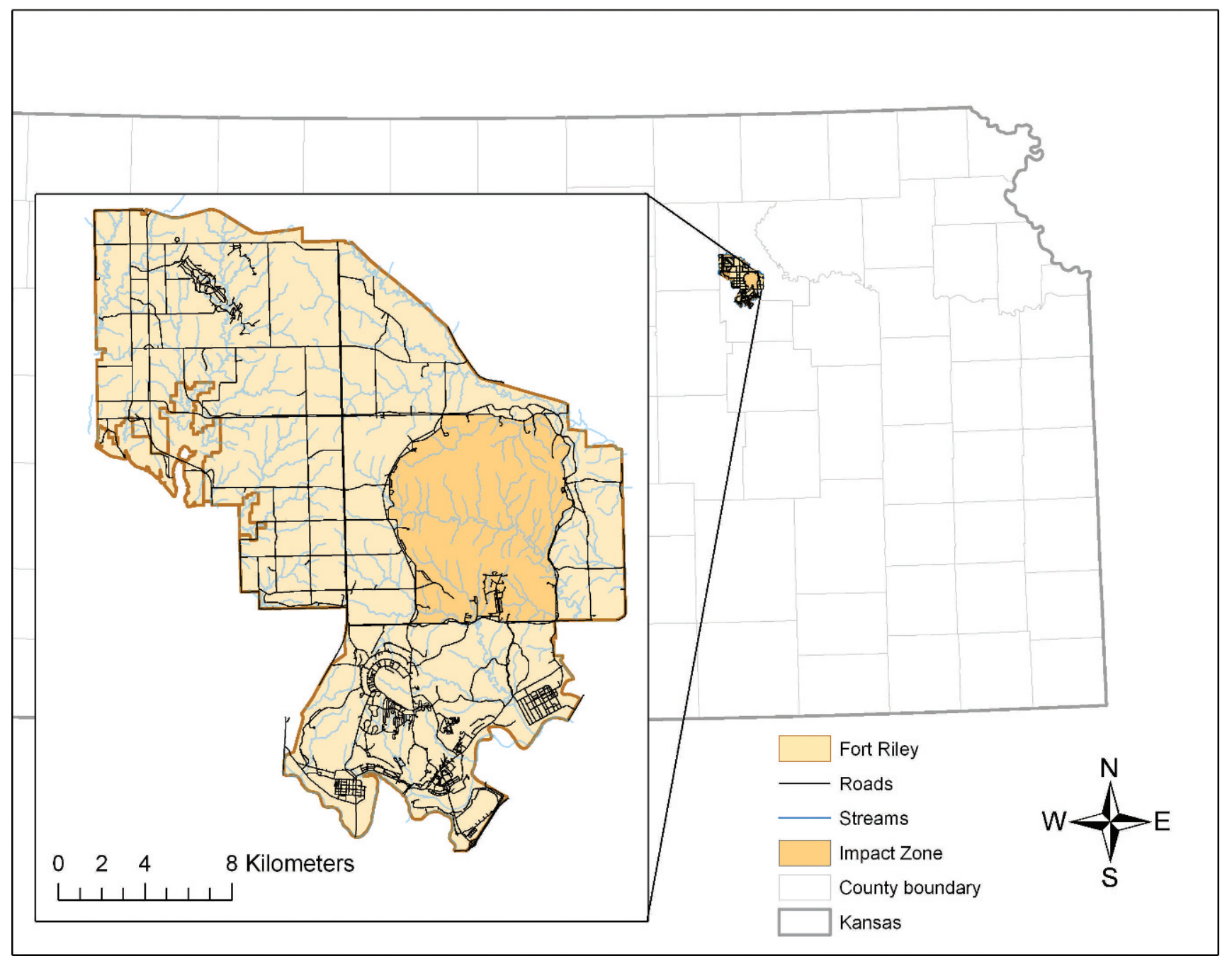

Figure 1. Location of Fort Riley Military Installation, Kansas, including streams, roads, and location of range-firing impact area (Impact Zone).

subsequent capture periods. Following capture, we used radio-telemetry to monitor survival of elk until mortality occurred, collars failed, or collars were removed. The study period during which we conducted radio-telemetry was November 2003 to February 2007. We located all radio-marked elk one to two times per week to monitor survival. We estimated the locations of elk that were equipped with VHF radio-collars based on triangulation of greater than two signal bearings taken from known geographic locations within a 10-20-min time period. During telemetry monitoring, we located elk using a 3-element Yagi antenna and took compass bearings in the direction of the strongest VHF signal. Geographic coordinates were recorded using a Garmin eTrex GPS unit at the location from which each compass bearing was taken. Geographic locations and compass bearings were used to estimate elk locations using the Program LOCATE II (Nams 1990).

\section{Survival analyses}

We estimated monthly survival rates using the 'nest survival' model in Program MARK (White and Burnham
1999; Dinsmore et al. 2002). The 'nest survival' model is a known-fate procedure that can be used to estimate survival rates based on telemetry data collected at irregular intervals (Hartke et al. 2006; Mong and Sandercock 2007). Encounter histories for each elk were coded with four variables: the month following collar deployment $(k)$, the last month that an elk was known to be alive $(I)$, the month during which an elk died or was no longer able to be located $(m)$, and the fate of each elk ( $f$, 1 = died, 0 = survived; Table S1, Supplemental Material). We coded the month following collar deployment as the initial monthly interval $(k)$. We used this approach because several capture periods occurred near the end of a given month, so survival to the beginning of the next month would not reflect survival over a full monthly time period and could bias survival estimates high.

Environmental covariates used for modeling elk survival included an index of hunter access (average number of days per month that training areas were open for hunting during hunting season) and the total number of antlerless-only elk permits issued during a given season for elk harvest on Fort Riley (Table S2, Supplemental 


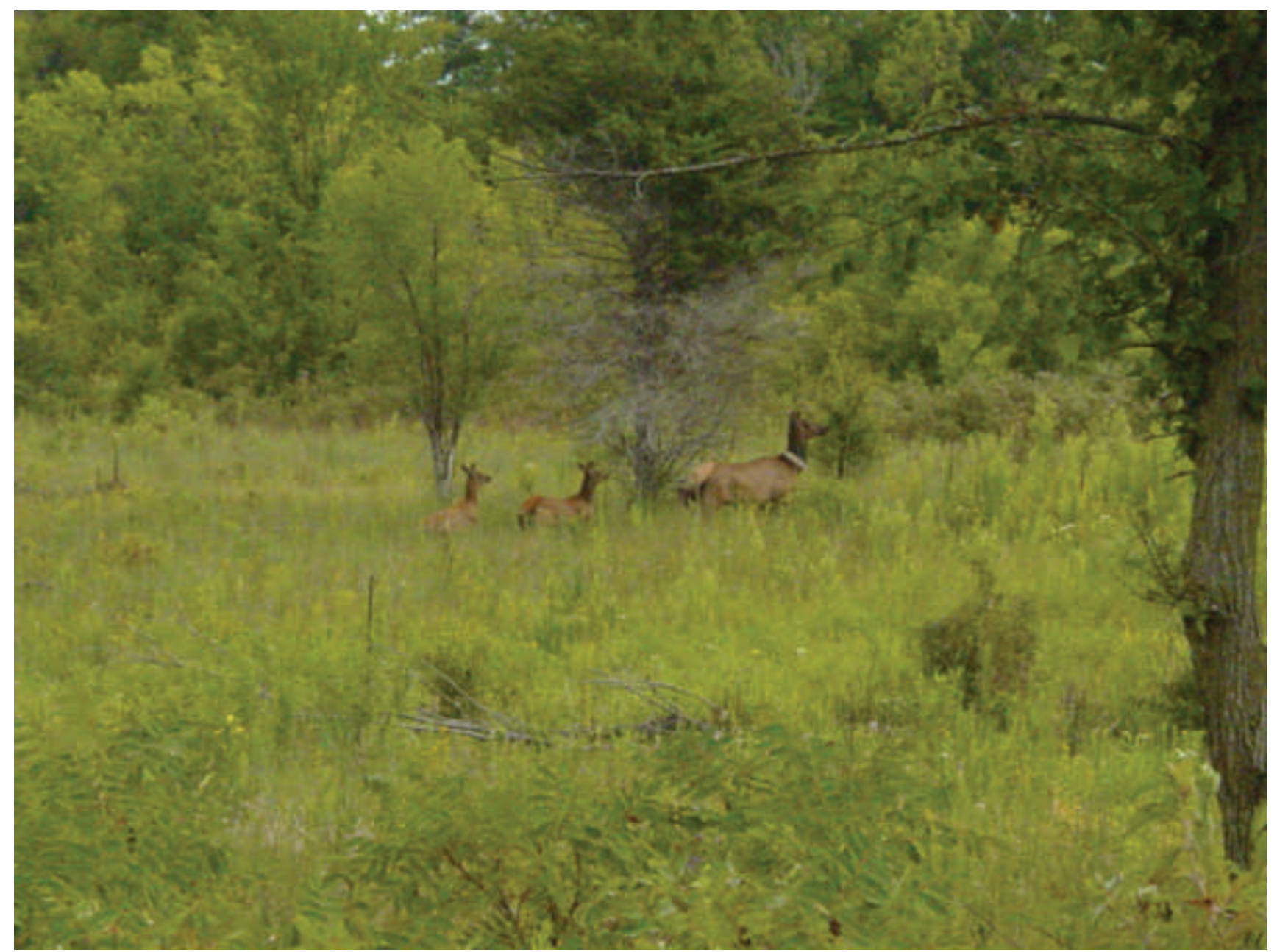

Figure 2. Female elk Cervus elaphus with a very high frequency radio-collar at Fort Riley, Kansas. Photo taken August 2004 by Nichole Lambrecht.

Material). We included an individual covariate for the proportion of telemetry locations $<500 \mathrm{~m}$ from the nearest publicly accessible road (Table S3, Supplemental Material). This distance was chosen because other studies indicate that elk may avoid areas within $500 \mathrm{~m}$ of roads (Witmer and deCalesta 1985). We also included the proportion of locations within the Impact Zone as a covariate because we felt that the Impact Zone could potentially serve as a refuge for elk from hunting and could therefore influence survival rates. We calculated these individual covariates based on locations of elk obtained from triangulation (VHF collars) or GPS fixes (GPS collars).

We included an individual covariate for average percent ingesta-free body fat in candidate models because ingesta-free body fat has been demonstrated to influence survival of elk in other settings (Bender et al. 2008; Table S3, Supplemental Material). The level of ingesta-free body fat was estimated based on rump body conditions scores and subcutaneous rump-fat thickness levels (Cook et al. 2001). Individual covariate values for average body-fat levels were calculated as the mean value across all capture occasions during which an individual elk was captured or recaptured. Female elk were captured one $(N=22)$, two $(N=9)$, or three $(N=$ 3) times during the study period.

We modeled age as a time-varying individual covariate (Cooch and White 2012). We also included a model with age as a quadratic effect to test for possible senescence. We assigned a mean annual age value for adult elk captured during corral trapping and elk from which we did not acquire a tooth. We coded annual values for age as separate columns in the encounter-histories file, and we coded the design matrix so that elk were considered to remain the same age from 1 October to 30 September of the following year. Although we avoided capturing elk that were $<1$ y old, we believe that adult age classes of captured elk were representative of the Fort Riley population.

In instances where individual covariate values were missing, we assigned individual elk the overall mean value for that covariate (Cooch and White 2012). For example, this situation occurred for four elk that were harvested by hunters before telemetry locations could be collected, and these elk were assigned the overall mean value for proportion of locations $<500 \mathrm{~m}$ from the 
road (0.34) and proportion of locations in woodlands (0.38). However, available information (capture locations, recorded sightings, mortality locations) indicated that each of these elk were initially captured, lived, and died $>6 \mathrm{~km}$ outside of the Impact Zone. When modeling, we assigned these elk a proportion of locations in the Impact Zone of '0.'

We selected an a priori suite of models $(N=38)$ for inclusion in the candidate model set (Table S4, Supplemental Material). We selected the particular suite of candidate models because we believed that combinations of covariates found in these models were biologically relevant and reasonably could be expected to influence survival of elk (Johnson and Omland 2004). For models in the candidate set, we allowed survival rates to differ between months encompassing the hunting season (6 mo, 1 October-31 March) and nonhunting season (6 mo, 1 April-30 September). We expected that adult survival in a harvested population would differ between hunting season (1 October-15 March) and the rest of the year, and we held monthly survival constant within each period.

Model selection was based on examining differences in Akaike's Information Criterion corrected for small sample size $(\triangle \mathrm{AIC})$, Akaike weights $\left(w_{i}\right)$, and deviance. We considered models to be equally parsimonious if the difference between $\mathrm{AIC}_{c}$ values was $<2.0$ (Burnham and Anderson 2002). For top models $\left(\Delta \mathrm{AIC} C_{c}<2.0\right)$, we inferred that a parameter influenced survival rates if the 95\% confidence interval of the $\beta$ coefficient did not overlap zero and the parameter reduced the deviance of the model (Arnold 2010). To account for model selection uncertainty when examining temporal variation in monthly survival throughout the study period, we averaged monthly survival estimates from across the candidate model set using model-averaging procedures in Program MARK.

We estimated annual survival rates of female elk for two different time periods: October 2004-September $2005\left(\hat{s}_{2004-2005}\right)$ and October 2005-September 2006 $\left(\hat{s}_{2005-2006}\right)$. We also calculated an overall annual survival rate $\left(\hat{s}_{\text {overall }}\right)$ to include information from the entire study period. To estimate annual survival rates for each of these time periods, we constructed a model in which survival varied between hunting-season (OctoberMarch) and nonhunting-season months (April-September). Monthly survival rates were held constant at 1.0 for all nonhunting-season months because no collared elk died during these time periods. We estimated annual survival rates as a product of monthly hunting-season $\left(\hat{s}_{\text {hunt }}\right)$ and nonhunting-season ( $\left.\hat{s}_{\text {nonhunt }}\right)$ survival estimates within each time period:

$$
\hat{s}_{\text {annual }}=\left(\hat{S}_{\text {hunt }}\right)^{6} \times 1
$$

We calculated variance for annual and overall survival estimates with the delta method (Powell 2007). Nonhunting-season survival rates were held constant at 1.0, so variance calculations using the delta method were based on variance for hunting-season survival rates. Covariation or dependence between variables used to estimate overall and annual survival rates were not accounted for in these delta-method variance calculations because overall and annual estimates were derived from the product of only a single variable (hunting-season monthly survival estimates).

To accommodate the uncertainty associated with the fate of one elk that was lost during the study, we conducted an initial analysis with this elk coded as alive and removed from the analysis after the last recorded location and a second analysis with this elk considered to have died following the last recorded location (Murray 2006). Monthly survival estimates and model selection results were similar for both analyses; thus, only results for the analysis with this elk coded as dead are presented.

We attempted to contact hunters who held permits for Fort Riley between 2003 and 2006 to determine whether hunters preferentially harvested or avoided harvesting elk with collars. We were able to contact $\approx 26 \%$ of hunters that held permits to harvest elk on Fort Riley and conducted phone interviews with these hunters $(N=$ 20). During phone interviews, we first asked whether hunters observed elk with collars while hunting on Fort Riley. If hunters had observed collared elk, we asked whether the presence of a collar influenced the decision of the hunter to harvest a given animal. Hunters that harvested an elk $(N=5)$ indicated that selection for elk was based on availability (positioning and/or distance of a given animal in a way that allowed the opportunity for a successful shot), and that the presence of a collar on an elk was not a factor that influenced the decision to either harvest or not harvest a given animal. No hunters indicated that they preferentially harvested an elk due to the presence of a collar, although there was a single instance in which a hunter claimed to have avoided harvesting an elk due to the presence of a collar. Due to the strong desire to successfully harvest an elk that was expressed by hunters that we interviewed, we believe that avoiding an opportunity to harvest an elk solely based on the presence of a collar occurred only very rarely. However, avoidance of harvesting collared elk by hunters could result in survival estimates that were biased upward.

\section{Results}

Among 34 female elk tracked during this study, 24\% died during the study period and all causes of mortality were human-related. Five elk were harvested during the Fort Riley hunting season, one elk was legally harvested on private land adjacent to Fort Riley, one elk was found dead on Fort Riley during hunting season (presumably as a result of being wounded and not recovered; (Tom Duckworth, Fort Riley Conservation Officer, personal communication), and one female elk was euthanized by a Kansas Department of Wildlife and Parks conservation officer after reports of strange behavior. This individual was old and in poor nutritional condition, so the ultimate cause of death could also have been attributed to malnutrition-starvation.

We considered seven models to be equally parsimonious $\left(\triangle A I C_{c} \leq 2.0\right)$. Age was included as a variable in all 
Table 1. Top candidate models for monthly survival of female elk Cervus elaphus at Fort Riley, Kansas, in the 3.5-y period from November 2003 to February 2007. Model fit was assessed by number of parameters (K), deviance (Dev), AIC $c$ (Akaike's Information Criterion corrected for small sample size), and Akaike weight $\left(w_{i}\right)$.

\begin{tabular}{llllll}
\hline Model structure & $\boldsymbol{K}$ & $\mathbf{D e v}$ & $\mathbf{A I C}_{\boldsymbol{c}}$ & $\boldsymbol{\Delta} \mathbf{A I C}_{\boldsymbol{c}}$ & $\boldsymbol{w}_{\boldsymbol{i}}$ \\
\hline$S_{\text {AGE }}$ & 3 & 67.8 & 73.8 & 0.0 & 0.12 \\
$S_{\text {AGE + PERMITS }}$ & 4 & 66.1 & 74.2 & 0.3 & 0.10 \\
$S_{\text {AGE + OPEN AREAS }}$ & 4 & 66.6 & 74.7 & 0.9 & 0.08 \\
$S_{\text {NO COVARIATES }}$ & 2 & 71.1 & 75.1 & 1.3 & 0.06 \\
$S_{\text {AGE + IMPACT_ZONE }}$ & 4 & 67.6 & 75.7 & 1.8 & 0.05 \\
$S_{\text {AGE + AVG FAT }}^{2}$ & 4 & 67.6 & 75.7 & 1.9 & 0.04 \\
$S_{\text {AGE + AGE }}$ & 4 & 67.7 & 75.8 & 1.9 & 0.04 \\
\hline
\end{tabular}

top models that included covariates (Table 1). A single variable model with age as the main effect received the greatest amount of support among our set of candidate models (Table 1). Age had a slight but significant negative relationship with elk survival in the top model (Table 2). For all covariates other than age, the 95\% confidence intervals of $\beta$-coefficients overlapped 0 , which indicated that the inclusion of these covariates explained little additional variation in survival when compared with the top model $\left(S_{\text {age }}\right)$. The addition of covariates other than age also did little to reduce deviance; therefore, they were not considered to substantially improve model fit and should not be interpreted as having a strong relationship with survival.

The age at capture for elk of known age ranged from 1.5 y to 16.5 y old (Figure 3). Age-specific parameter estimates from the model $S_{\text {age }}$ indicated that elk survival generally decreased with age (Figure 4). Monthly survival rates during the hunting season were 0.98 for yearlings, with progressively lower survival rates for older females (Figure 4).

Although yearlings were included in our sample $(N=$ 8), all elk that were harvested during the study were adults ( $\geq 2.5 \mathrm{y}$ old; $N=6$ ). For female elk of known age that died as a result of legal harvest $(N=5)$, the estimated age at harvest ranged from $4.5 \mathrm{y}$ to $14.5 \mathrm{y}$ old, with an average age at harvest of 6.9 y (SE $=3.09$ ). The mean age at mortality for female elk dying from all

Table 2. $\beta$ coefficients for individual covariates included in models of monthly survival of female elk Cervus elaphus at Fort Riley, Kansas, 2003-2007.

\begin{tabular}{|c|c|c|c|}
\hline Model structure & Parameter & $\beta$ & $95 \% \mathrm{Cl}$ \\
\hline$S_{\text {AGE }}$ & AGE & -0.16 & $(-0.32,-0.001)$ \\
\hline \multirow[t]{2}{*}{$S_{\text {AGE }+ \text { PERMITS }}$} & AGE & -0.14 & $(-0.31,0.01)$ \\
\hline & PERMITS & -0.04 & $(-0.09,0.02)$ \\
\hline \multirow[t]{2}{*}{$S_{\text {AGE }}+$ OPEN AREAS } & AGE & -0.16 & $(-0.33,-0.001)$ \\
\hline & OPEN AREAS & -0.04 & $(-0.12,0.03)$ \\
\hline \multirow[t]{2}{*}{$S_{\text {AGE }}+$ IMPACT_ZONE } & AGE & -0.18 & $(-0.35,<0.01)$ \\
\hline & IMPACT_ZONE & -0.47 & $(-2.55,1.62)$ \\
\hline \multirow[t]{2}{*}{$S_{\text {AGE }}+$ AVG FAT } & AGE & -0.18 & $(-0.36,0.01)$ \\
\hline & AVG FAT & -0.04 & $(-0.26,0.18)$ \\
\hline \multirow[t]{2}{*}{$S_{A G E}+A_{G E}^{2}$} & AGE & -0.07 & $(-0.76,0.63)$ \\
\hline & $A G E^{2}$ & -0.01 & $(-0.04,0.03)$ \\
\hline
\end{tabular}

causes tended to be older $(\bar{x}=7.8 \mathrm{y}, \mathrm{SE}=2.76, N=7)$ than the mean age at capture for all elk $(\bar{x}=4.9, \mathrm{SE}=$ $0.98, N=25$ ).

The overall annual survival rate for the entire study period (November 2003-February 2007) was 0.76 (var $\left.\left[\hat{s}_{\text {overall }}\right]=0.005\right)$, with higher annual estimates of survival for 2004-2005 $\left(\hat{s}_{2004-2005}=0.83, \operatorname{var}\left[\hat{s}_{2004-2005}\right]\right.$ $=0.012)$ and $2005-2006\left(\hat{s}_{2005-2006}=0.89, \operatorname{var}\left[\hat{s}_{2005-2006}\right]\right.$ $=0.01)$. The lower overall annual survival rate was due to mortalities $(N=3)$ that occurred during the 2003 Fort Riley hunting season. Survival estimates were lower during hunting seasons for all years based on modelaveraged estimates from all candidate models (Figure 5). During hunting season, survival estimates were generally lower during all segments of the Fort Riley hunting season (October-December) when compared with time periods during which harvest was restricted to only private land (January-March; Figure 5). We did not observe any mortalities outside of the hunting season, but this may have been due to the relatively small size of our sample.

\section{Discussion}

Annual estimates of survival for the Fort Riley population exhibited temporal variation, but were within the range of survival estimates reported for elk survival in other areas (Unsworth et al. 1993; Stussy et al. 1994; Kunkel and Pletscher 1999; Bender et al. 2008). Annual survival estimates for adult female elk ranged from 0.78 to 1.0 in Idaho (Unsworth et al. 1993), 0.82 to 0.96 in Oregon (Stussy et al. 1994), 0.99 in northern Arizona (Ballard et al. 2000), 0.64 to 0.88 in Montana (Kunkel and Pletscher 1999), and 0.74 to 1.0 across populations in Washington and Oregon (Bender et al. 2008). The overall survival estimate at Fort Riley (0.76) was lower than the overall average female adult survival rate (0.87) reported for 12 elk studies in the western United States (Raithel et al. 2007).

Monthly survival rates differed between the hunting and nonhunting season, which supported our predictions for a southerly population where harvest was the primary cause of mortality. The higher survival rates observed during the period in which harvest was allowed only on private lands around Fort Riley (January-March) were likely due to risk-sensitive movements by female elk, which spent little time on private lands during late winter (Conard 2009). 


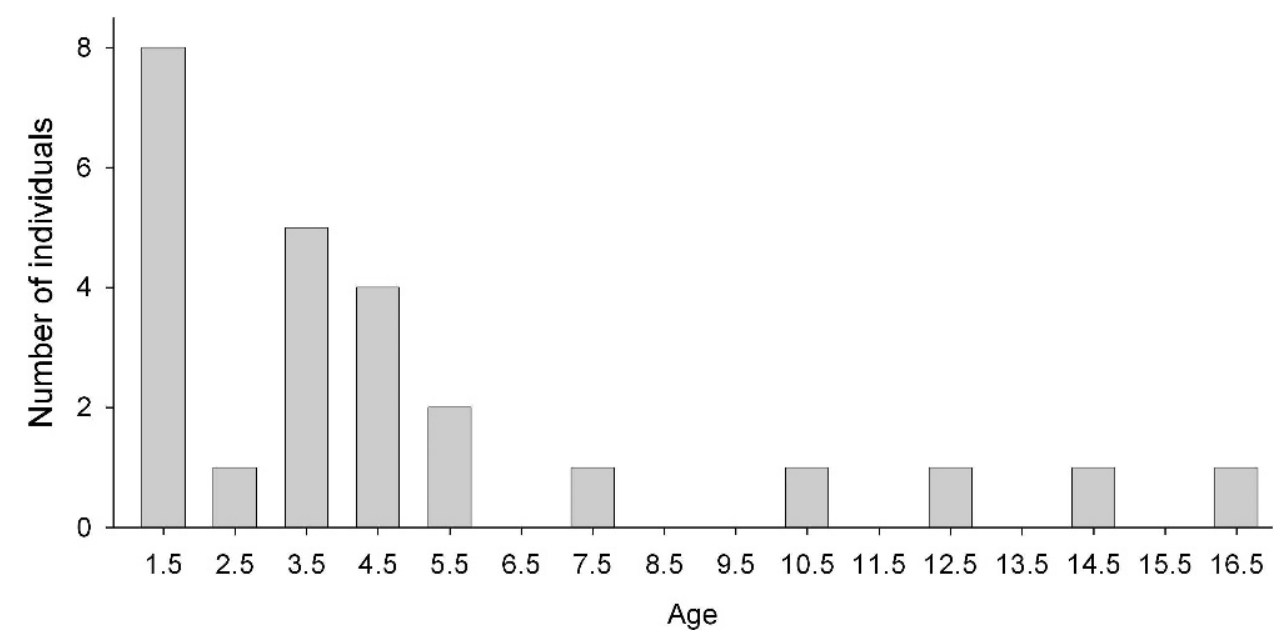

Figure 3. Age at capture for female elk Cervus elaphus $(N=25)$ at Fort Riley, Kansas, October 2003-April 2006.

The main cause of mortality for female elk was legal harvest or harvest-related injury, which is similar to mortality causes in other harvested populations (Unsworth et al. 1993; Ballard et al. 2000). No mortality directly due to predation or other natural causes was documented during the course of this study. Coyotes Canis latrans are abundant in the study area and may be capable of preying on calf or yearling elk (Walter et al. 2005), but they were not a cause of mortality for adult female elk.

Artillery firing, range firing, and vehicle collisions can constitute a major source of mortality for ungulates on military installations (Dinkines et al. 1992). However, we observed no mortality of elk related to military training despite extensive use of the Impact Zone and other training areas by elk throughout the study period (Conard 2009). Although further research would be needed to determine the specific mechanisms by which elk avoid mortality from artillery and range-firing, one possibility is that elk move away from firing areas or out of the Impact Zone during times when firing actively occurs. It is also possible that there is a relatively low probability of elk directly encountering live fire in the Impact Zone and that they simply habituate to military training activities (i.e., Telesco and Van Manen 2006). Although we observed no direct effects of military training on survival of elk, military training can influence the composition of forage plants and alter behavior and habitat use patterns of ungulates (Stephenson et al. 1996; Quist et al. 2003), which would indirectly influence survival rates and population dynamics.

Environmental conditions, predation, and military training activities are secondary to harvest as a source of mortality in the Fort Riley population. As the primary source of mortality, hunting is expected to directly influence adult survival rates, which may subsequently

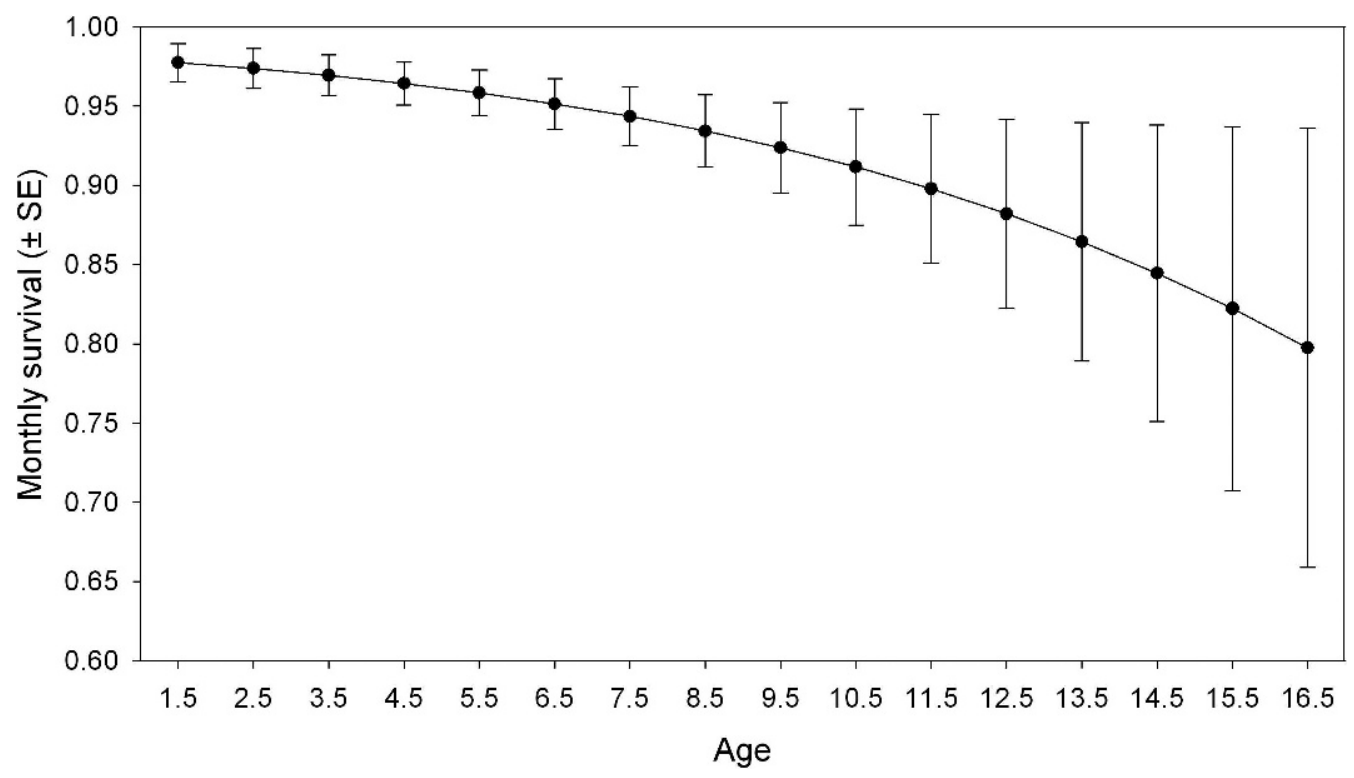

Figure 4. Age-specific monthly survival estimates $( \pm \mathrm{SE})$ for female elk Cervus elaphus from the model $S_{\text {age }}$ during hunting seasons at Fort Riley, Kansas, 2003-2006. 


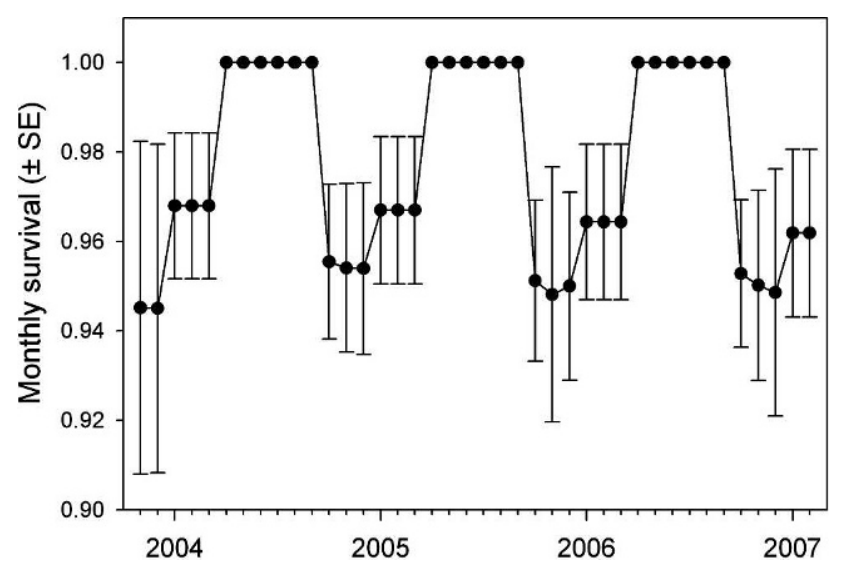

Figure 5. Model-averaged estimates of monthly female elk Cervus elaphus survival ( \pm SE) at Fort Riley, Kansas, November 2003-February 2007.

influence the overall rate of population growth $(\lambda)$. Harvest may have a particularly strong influence on population dynamics if prime-age classes are selectively harvested (Wright et al. 2006).

Variation in female elk survival rates was not wellexplained by the covariates that we examined in candidate models, although this lack of an observed relationship may have been due in part to our small sample size. We found that age was the only covariate included in top models with a significant relationship to survival. We found a weak negative relationship between age and survival, which was consistent with age-specific variation in survival found in other ungulate populations (Loison et al. 1999; Gaillard et al. 2000; Festa-Bianchet et al. 2003). A negative relationship between survival and age in the Fort Riley population could be due to hunters avoiding harvesting a calf or yearling, and thereby increasing the mortality risk for adult female elk in older age-classes (Wright et al. 2006). The average age at harvest for female elk at Fort Riley $(\bar{x}=6.9$ y) was within what has been defined as the prime-age life stage for elk (2-9 y; Raithel et al. 2007), and is similar to the average age of elk harvested from a population in Idaho $(\bar{x}=$ 7.3 y; Husseman et al. 2003).

Adult female survival is often the demographic vital rate with the greatest influence on variation in population growth rate $(\lambda)$ in ungulate populations (Gaillard et al. 2000; Eberhardt 2002). For populations with hunting as the primary source of mortality, management actions and harvest limits are often used as a tool for managing rates of population change. However, survival of female elk did not appear to be influenced by the number of permits issued, at least within the range of variation in the number of hunting permits issued during our study. This suggests that the number of permits issued would have to vary beyond what we observed during the study period to potentially have a measurable impact on adult survival in this population. Our findings suggest that modest annual variation in harvest management strategies may not always have a strong direct influence on prime-age survival rates. Further study of hunter behavior in relation to habitat use by elk may be useful for linking the impacts of harvest regulations to the survival of elk in harvested populations.

\section{Supplemental Material}

Please note: The Journal of Fish and Wildlife Management is not responsible for the content or functionality of any supplemental material. Queries should be directed to the corresponding author for the article.

Table S1. Encounter histories for elk Cervus elaphus included in survival analysis. Includes information on dates of collar deployment, dates each elk was last known to be alive, dates of mortality, and fate of each elk.

Table S2. Environmental covariates used in elk Cervus elaphus data analysis, including the average number of days that training areas were accessible during hunting season and the total number of antlerless-only permits issued for a given hunting season on Fort Riley.

Table S3. Individual covariate values used in data analysis, including data for each elk Cervus elaphus on the proportion of locations $<500 \mathrm{~m}$ from the nearest road, proportion of locations in the Impact Zone, average percent body fat, and estimated age.

Table S4. List of all candidate models used for elk Cervus elaphus survival analysis.

All Supplemental Tables found at DOI: http://dx.doi. org/10.3996/082011-JFWM-050.S1 (14 KB XLSX).

\section{Acknowledgments}

Funding was provided by the Rocky Mountain Elk Foundation, U.S. Army Construction Engineering Research Laboratory, U.S. Geological Survey, Kansas Cooperative Fish and Wildlife Research Unit, Fort Riley Conservation Department, and Safari Club International.

We thank members of the Fort Riley Conservation Department, Nichole Lambrecht, and Rocky Fahey for field assistance. We thank L.C. Bender for leading capture efforts and providing analysis advice. We thank the Subject Editor and anonymous reviewers for providing constructive comments that improved the manuscript.

Any use of trade, product, or firm names is for descriptive purposes only and does not imply endorsement by the U.S. Government.

\section{References}

Arnold TW. 2010. Uninformative parameters and model selection using Akaike's Information Criterion. Journal of Wildlife Management 74:1175-1178.

Ballard WB, Whitlaw HA, Wakeling BF, Brown RL, DeVos JC, Wallace MC. 2000. Survival of female elk in northern Arizona. Journal of Wildlife Management 64:500-504.

Beissinger SR, Westphal MI. 1998. On the use of demographic models of population viability in endangered species management. Journal of Wildlife Management 62:821-841.

Bender LC, Cook JG, Cook RC, Hall PB. 2008. Relations between nutritional condition and survival of North American elk. Wildlife Biology 14:70-80. 
Bender LC, Davison MA, Cook JG, Cook RC, Hall PB. 2006. Assessing elk population status and potential performance in the Nooksack area, Washington. Northwestern Naturalist 87:98-106.

Bender LC, Lomas LA, Browning JB. 2007. Condition, survival, and cause-specific mortality of adult female mule deer in north-central New Mexico. Journal of Wildlife Management 71:1118-1124.

Beringer J, Seibert SG, Reagan S, Brody AJ, Pelton MR, Vangilder LD. 1998. The influence of a small sanctuary on survival rates of black bears in North Carolina. Journal of Wildlife Management 62:727-734.

Burnham KP, Anderson DR. 2002. Model selection and multi-model inference: a practical information-theoretic approach. 2nd edition. New York: Springer Verlag.

Cole EC, Pope MD, Anthony RA. 1997. Effects of road management on movement and survival of Roosevelt elk. Journal of Wildlife Management 61:1115-1126.

Conard JM. 2009. Genetic variability, demography, and habitat selection in a reintroduced elk (Cervus elaphus) population. Doctoral dissertation. Manhattan: Kansas State University. Available: http://hdl.handle.net/2097/ 1515 (August 2011).

Cooch E, White G. 2012. Program Mark: a gentle introduction. 11th edition. Available: http://www. phidot.org/software/mark/docs/book (August 2011).

Cook RC, Cook JG, Murray DL, Zager P, Johnson BK, Gratson MW. 2001. Development of predictive models of nutritional condition for Rocky Mountain elk. Journal of Wildlife Management 65:973-987.

De Kroon H, Van Groenendael J, Ehrlen J. 2000. Elasticities: a review of methods and model limitations. Ecology 81:607-618.

DelGiudice GD, Riggs MR, Joly P, Pan W. 2002. Winter severity, survival, and cause specific mortality of female white-tailed deer in north-central Minnesota. Journal of Wildlife Management 66:698-717.

Dimmick RW, Pelton MR. 1996. Criteria of sex and age. Pages 169-214 in Bookhout TA, editor. Research and management techniques for wildlife and habitats. Bethesda, Maryland: The Wildlife Society.

Dinkines WC, Lochmiller RL, Bartush WS, DeYoung CA, Qualis CW Jr, Fulton RW. 1992. Cause-specific mortality of white-tailed deer as influenced by military training activities in southwestern Oklahoma. Journal of Wildlife Diseases 28:391-399.

Dinsmore SJ, White GC, Knopf FL. 2002. Advanced techniques for modeling avian nest survival. Ecology 83:3476-3488.

Eberhardt LL. 2002: a paradigm for population analysis of long-lived vertebrates. Ecology 83:2841-2854.

Festa-Bianchet M, Gaillard J-M, Cóte SD. 2003. Variable age structure and apparent density dependence in survival of adult ungulates. Journal of Animal Ecology 72:640-649.

Gaillard J-M, Festa-Bianchet M, Yoccoz NG, Loison A, Toigo C. 2000. Temporal variation in fitness components and population dynamics of large herbivores. Annual Review of Ecology and Systematics 31:367-393.
Gratson MW, Whitman CL. 2000. Road closures and density and success of elk hunters in Idaho. Journal of Wildlife Management 28:302-310.

Hartke KM, Grand JB, Hepp GR, Folk TH. 2006. Sources of variation in survival of breeding female wood ducks. Condor 108:201-210.

Hayes SG, Leptich DJ, Zager P. 2002. Proximate factors affecting male elk hunting mortality in northern Idaho. Journal of Wildlife Management 66:491-499.

Husseman JS, Murray DL, Power G, Mack C, Wenger CR, Quigley H. 2003. Assessing differential prey selection patterns between two sympatric large carnivores. Oikos 101:591-601.

Johnson JB, Omland KS. 2004. Model selection in ecology and evolution. Trends in Ecology and Evolution 19: 101-108.

Kunkel K, Pletscher DH. 1999. Species-specific population dynamics of cervids in a multipredator ecosystem. Journal of Wildlife Management 63:1082-1093.

Larkin JL, Maehr DS, Cox JJ, Bolin DC, Wichrowski MW. 2003. Demographic characteristics of a reintroduced elk population in Kentucky. Journal of Wildlife Management 67:467-476.

Loison A, Festa-Bianchet M, Gaillard J-M, Jorgenson JT, Jullien J-M. 1999. Age specific survival in five populations of ungulates: evidence of senescence. Ecology 80:2539-2554.

Mong TW, Sandercock BK. 2007. Optimizing radio retention and minimizing radio impacts in a field study of upland sandpipers. Journal of Wildlife Management 71:971-980.

Morris WF, Doak DF. 2002. Quantitative conservation biology: theory and practice of quantitative population viability analysis. Sunderland, Massachusetts: Sinauer.

Moyes K, Coulson T, Morgan JT, Donald A, Morris SJ, Clutton-Brock TH. 2006. Cumulative reproduction and survival costs in female red deer. Oikos 115:241-252.

Murray DL. 2006. On improving telemetry-based survival estimation. Journal of Wildlife Management 70:1530-1543.

Nams VO. 1990: locate II user's guide. Truro, Nova Scotia, Canada: Pacer Computer Software.

Nelson LJ, Peek JM. 1982. Effect of survival and fecundity on rate of increase of elk. Journal of Wildlife Management 46:535-540.

Pitts RM, Levally MJ, Klinger S. 1987. Mammals of Fort Riley, Kansas. Transactions of the Kansas Academy of Science 90:75-80.

Powell LA. 2007. Approximating variance of demographic parameters using the delta method: a reference for avian biologists. Condor 109:949-954.

Quist MC, Fay PA, Guy CS, Knapp AK, Rubenstein BN. 2003. Military training effects on terrestrial and aquatic communities on a grassland military installation. Ecological Applications 13:432-442.

Raedeke KJ, Millspaugh JJ, Clark PE. 2002. Population characteristics. Pages 449-452 in Toweill DE, Thomas JW, editors. North American elk: ecology and management. Washington, D.C.: Wildlife Management Institute. 
Raithel JD, Kauffman MJ, Pletscher DH. 2007. Impact of spatial and temporal variation in calf survival on the growth of elk populations. Journal of Wildlife Management 71:795-803.

Solberg EJ, Loison A, Saether B-E, Strand O. 2000. Age specific harvest mortality in a Norwegian moose Alces alces population. Wildlife Biology 6:41-52.

Stephenson TR, Hundertmark KJ, Schwartz CC, Van Bellenberghe V. 1998. Predicting body fat and body mass in moose with ultrasonography. Canadian Journal of Zoology 4:717-723.

Stephenson TR, Vaughan MR, Anderson DE. 1996. Mule deer movements in response to military activity in southeastern Colorado. Journal of Wildlife Management 60:777-787.

Stussy RM, Edge WD, O'Neil TA. 1994. Survival of resident and translocated female elk in the Cascade Mountains of Oregon. Wildlife Society Bulletin 22: 242-247.
Telesco DJ, Van Manen FT. 2006. Do black bears respond to military training? Journal of Wildlife Management 70:222-230.

Unsworth JW, Kuck L, Scott MD, Garton EO. 1993. Elk mortality in the Clearwater drainage of northcentral Idaho. Journal of Wildlife Management 57:495-502.

Walter WD, Bryant RM, Leslie DM Jr. 2005. Unusual documentation of elk behaviors using automated cameras. Proceedings of the Oklahoma Academy of Science 85: 81-83.

White GC, Burnham KP. 1999. Program MARK: survival estimation from populations of marked animals. Bird Study (Supplement) 46:120-138.

Witmer GW, deCalesta DS. 1985. Effect of forest roads on habitat use by Roosevelt elk. Northwest Science 59: 122-125.

Wright GJ, Peterson RO, Smith DW, Lemke TO. 2006. Selection of northern Yellowstone elk by gray wolves and hunters. Journal of Wildlife Management 70:1070-1078. 